\title{
Para unha historia da educación teatral en Galicia. Aspectos básicos
}

\author{
For a History of Theatre Education in Galicia. Basic features.
}

\author{
Manuel F. VIEITES \\ Escola Superior de Arte Dramática de Galicia \\ Facultade de Ciencias da Educación, Universidade de Vigo \\ mvieites@uvigo.es
}

\begin{abstract}
RESUMO: Na construción e configuración de calquera sistema do campo cultural, faise necesario, entre outras cousas, o desenvolvemento de institucións que o estruturen e nutran. No caso do teatral, son especialmente importantes aquelas nas que se forman os axentes do sistema, e, entre elas, destacan as escolas de teatro, centros de formación que poden desenvolver procesos educativos diversos, con maior ou menor grao de formalización, aínda que 0 ámbito da educación teatral é maior, como queremos mostrar. Neste traballo, que situamos ao abeiro da Historia da educación teatral, queremos ofrecer unha panorámica xeral do que teñen sido as liñas de traballo máis importantes no ámbito da formación teatral en Galicia, e que, no seu conxunto, configuran un campo de estudo e investigación emerxente.
\end{abstract}

PALABRAS CLAVE: Educación teatral, Historia da educación teatral, Escolas de teatro, Teatro na escola

\begin{abstract}
In the making and development of any of the systems of the cultural field, there are institutions which are very relevant, as far as the whole process depends on them. In the case of the theatre system, those institutions oriented to the training of the agents of the system are especially important, and among them we must consider the theatre schools which offer different types of courses and qualifications, with a different degree of formalization, although the field that theatre education covers is much broader. This paper, which has been written under the framework of the History of Theatre Education, offers a general view of what have been the most popular issues in theatre education in Galicia in the past and at present, and at the same time shows the richness and possibilities of this new area of studies.
\end{abstract}

KEY WORDS: Theatre Education, History of Theatre Education, Theatre Schools, Theatre in Education

Estamos ante un territorio complexo, non tanto polas dificultades que poida entrañar a súa exploración e cartografía, que as hai, canto pola diversidade de manifestacións a que dá lugar o sintagma educación teatral; unhas dificultades que aumentan aínda máis ao 
considerarmos que estamos nun país, e falo do que chamamos Galicia, que forma parte doutro chamado España, onde a educación teatral nin está normativizada no seu conxunto, nin está normalizada, polo que a docencia e a investigación no campo son claramente deficitarias, comparando o que aquí acontece co que ocorre noutros países do mundo. ${ }^{1}$ Por todo iso, cabería falar tanto do que temos como do que aínda non temos, e do que quizais xamais chegaremos a ter.

Hai anos, Antón Figueroa ${ }^{2}$ dicía que Galicia, no cultural, era un país en obras, pero tamén o é en moitas outras cousas. E falar de obras, no noso caso, supón falar (a) das que se están a facer, para termos as infraestruturas ou os equipamentos necesarios (e fanse ben poucas), (b) das que non se están facendo e poida que nunca se fagan (porque se fan outras que xamais se deberían ter comezado), pero tamén (c) dalgunhas demolicións importantes en curso nos eidos da educación e da cultura. No caso do teatro e do sistema teatral seguimos en obras, aínda que deberiamos dicir máis ben que estamos ante un sistema incompleto, deficiente, insostible..., ao punto de que Galicia, ou España, non deixan de ser, insistimos, unha anomalía en Europa. Digamos, simplemente, a modo de exemplo, que os edificios teatrais non son centros de creación, que se dedican, no mellor dos casos, ao tránsito de mercadorías de todo tipo, e, entre elas, de espectáculos escénicos. ${ }^{3} \mathrm{E}$ para dirixir un teatro non se precisa máis formación que a que se demanda para un posto de cabo de intendencia, como denunciara no seu día un coñecido ilustrado español. ${ }^{4}$

Nestas circunstancias temos que falar de educación teatral, na súa historia e no seu presente, tendo en conta que esa educación forma parte dun sistema, o educativo, que inflúe noutro, o teatral, que en Galicia existe só como sintagma, polo que utilizamos a palabra sistema para designar un campo no que acontecen cousas, pero que non o sería de considerarmos cun certo rigor os seus elementos, estruturas, e as funcións que cumpren uns e outras. ${ }^{5}$ Queremos reiterar ${ }^{6}$ que, na nosa visión do teatro como sistema, partimos

1 No número 133, de novembro/decembro de 2010, da revista $A D E / T e a t r o$, publicabamos un editorial titulado, precisamente, "Queremos ser europeos. De la crisis en las artes escénicas", na que explicabamos como en materia teatral, e no propio ensino teatral, España é unha "anomalía" en Europa, polo pobre desenvolvemento que padecen ambos campos, o da educación e o da creación teatral, froito dunhas políticas educativas e culturais totalmente inadecuadas ao seu obxecto.

2 Vid., Nación, literatura, identidade, Vigo, Edicións Xerais, 2001.

3 VIEITES, Manuel F., "Modelos de gestión de los espacios escénicos en Europa", ADE/Teatro, número 109, 2006, pp. 123-145.

4 Leandro FERNÁNDEZ DE MORATÍN, contra finais do século XVIII, sinalaba en relación coa dirección de teatros, que "si a un insigne escritor no se le da jamás el mando de una provincia, ni a ningún excelente músico se le fía una escuadra, ¿por qué ha de ponerse en manos de un jefe militar la dirección de un teatro, empresa tan diferente de su profesión y tan superior a sus conocimientos?" En Los Moratines, obra en varios volumes que recolle a obra do pai, Nicolás, e a do fillo, Leandro, con edición de Jesús PÉREZ-MAGALLÓN, publicados en Madrid por Cátedra; a referencia procede do tomo I, pp. 187-188, en "Notas del Autor a La Comedia nueva". 5 FERNÁNDEZ VIEITES, M., "As artes escénicas en Galicia. Elementos para unha diganose", en Víctor F. FREIXANES e Alberto MEIXIDE, (eds.), O Capital da cultura: unha achega ás industrias culturais de Galicia, A Coruña, Fundación Caixa Galicia, 2010, pp. 463-537.

6 Non seguimos as propostas de Itamar EVEN-ZOHAR en torno ao que en 1979 define como polisistema, nun artigo titulado "Polysystem Theory" e publicado no número 1 da revista Poetics Today (pp. 287-310). Unha teoría que en España tivo especial eco na Universidade de Santiago de Compostela, e que daría lugar a un libro no 
das formulacións de investigadores que veñen contribuíndo a desenvolver o que L. von Bertalanffy definiu como "teoría xeral de sistemas", e das contribucións da escola sistémi$\mathrm{ca}^{7}$ que se forma no ámbito das ciencias sociais, humanas, ou da conduta. ${ }^{8}$

En relación con isto último, co paradigma elixido na consideración do sistema teatral e dos procesos educativos que no mesmo se producen, e que poden provocar comentarios de conmiseración entre os espíritos máis avanzados (ou en aparencia máis avanzados), tres comentarios breves. 0 primeiro, tomando palabras prestadas de Edgar Morin, quen dicía que "no sólo el objeto debe ser adecuado a la ciencia, sino que la ciencia debe ser adecuada al objeto"; 9 no segundo as palabras son de Mario Bunge, coñecido polos seus estudos sobre epistemoloxía, quen afirmaba que "puesto que el mundo es un sistema, también debe serlo nuestro conocimiento del él", pero que ademais alertaba ante os perigos de determinados paradigmas coma o denominado "textualista", afirmando que "la tesis de que todo es un texto o un discurso no sólo es errónea, sino también malvada 0 incluso enferma"; ${ }^{10}$ co terceiro lembramos a Alan Sokal e a Jean Bricmont, dous científicos que mostraban imposturas intelectuais moi abundantes nalgunhas correntes críticas tidas por novas, que destacan pola reciclaxe de discursos, e a reversión ou a invención de palabras e conceptos, para xerar unha densidade expositiva que se torna balbordo, pois, eses discursos "si parecen incomprensibles, es por la sencilla razón de que no quieren decir nada". ${ }^{11}$ Somos sistémicos porque somos modernos (non posmodernos), e aspiramos, con toda a humildade, a xerar coñecemento contrastado sobre a realidade que nos ocupa.

\section{Puntos de partida}

Ao falar de educación teatral habería que comezar por definir o que é a tal educación, considerar as súas características (como as posúen a educación deportiva, musical, plástica...) e as súas tipoloxías. Habería que considerar finalidades e obxectivos en cada tipoloxía, sen esquecer os seus tempos, espazos, usuarios, normativas, programas ou institucións. $^{12} \mathrm{E}$ todo iso cabería facelo na sincronía, no corte temporal que supón o estarmos situados en outubro de 2012, ou na diacronía, o que nos pode levar a considerar

que Montserrat IGLESIAS SANTOS recolle traballos de diversos autores: Teoría de los Polisistemas, Madrid, Arco Libros, 1999.

7 WINKIN, Y., "Una universidad invisible", en La nueva comunicación, Barcelona, Kairós, 1984. Colectánea que recolle traballos de Gregory BATESON, Erving GOFFMAN ou Paul WATZLAWICK.

8 BERTALANFFY, L. von, Teoría general de sistemas, Madrid, Fondo de Cultura Económica, 1976; LUHMANN, Niklas, Sociedad y sistema: la ambición de la teoría, Barcelona, Paidós, 1990.

9 MORIN, Edgar, Introducción al pensamiento complejo, Barcelona, Gedisa, 1996, p. 81

10 BUNGE, Mario, Crisis y reconstrucción de la filosofía, Barcelona, Gedisa, 2002, pp. 57, 53.

11 SOKAL, A., e BRICMONT, J., Imposturas intelectuales, Barcelona, Paidós, 1999, p. 23.

12 Unha primeira abordaxe dese tema podemos atopalo en VIEITES, M. F., "Educación teatral e estudos de Arte dramática", publicado en Arte dramática e función docente, volume editado con Felipe TRILLO e José Antonio CARIDE, e publicado en Santiago polo Consello da Cultura Galega en 2005, pp. 15-138. Volvemos considerar a cuestión en: "Después de la LOE. Presente y futuro de la Educación teatral en España en los inicios del siglo XXI", Don Galán, Revista de Investigación Teatral, número 2, 2012, http://teatro.es/contenidos/donGalan/ donGalanNum2/sumario.php 
secuencias temporais, e considerar a aparición e o desenvolvemento desas tipoloxías en Galicia. Así ocorre, por exemplo, coa historia dos conservatorios de música e declamación ${ }^{13}$ ou coa historia do teatro escolar, campo este con notables experiencias que datan de moito tempo atrás. ${ }^{14}$

Ao falarmos de educación teatral en Galicia, habería que considerar varias etapas, en función sobre todo dos procesos de configuración ou de reconfiguración dun sistema teatral propio, ${ }^{15}$ tarefa non concluída. Para os efectos do presente traballo, poderiamos tomar en conta tres grandes etapas: (1) a que chega ata 1936, ${ }^{16}$ (2) a que vai de 1936 a 1978 , e (3) a que vai de 1978 ao presente. ${ }^{17}$ Seguramente cabería pensar outros períodos con outras variables, mais para mostrar o conxunto nunha primeira panorámica a proposta pode servir, como xa temos explicado en traballos diversos. ${ }^{18}$

Cómpre sinalar igualmente que este traballo se sitúa a medio camiño entre dúas disciplinas fundamentais que se ocupan do teatral nunha perspectiva educativa, a Pedagoxía teatral ${ }^{19}$ (ou teoría da educación teatral) ${ }^{20}$ e a Historia da educación teatral, ${ }^{21}$ en tanto son as que ofrecen unha visión máis teorética e histórica do campo. Son disciplinas novas, moi recentes nos nosos escenarios educativos e académicos, sen apenas desenvolvemento e sen un corpus de traballos que definan os seus conceptos e discursos, as súas metodoloxías, ou nos sinalen camiños por medio de boas prácticas.

Por iso, este traballo ten tanto de prospectiva histórica como de consideración dos criterios a ter en conta para realizar unha tal prospectiva, e dos pasos primeiros a dar na

13 Está por escribir a historia dos conservatorios en Galicia, e máis concretamente a historia das seccións de declamación nos mesmos, de ter existido como tales, pois aí teriamos o primeiro xermolo da educación teatral especializada e profesional.

14 Camiñamos pola senda da historia das institucións dun determinado sistema, que tan bos resultados ten dado no campo da historia dos teatros, das compañías ou dos repertorios. Para o caso dos conservatorios, Vid., FERNÁNDEZ, Santiago, "Grupo do Conservatorio Profesional de Música e Declamación da Coruña", Casahamlet, número 2, 2000, pp. 30-31. No caso do teatro escolar, hai estudos moi diversos: CERVERA BORRÁS, Juan, Historia crítica del teatro infantil Español, Madrid, Editora Nacional, 1982; GONZÁLEZ MONTAÑÉS, Julio I., "El teatro de los Jesuitas en Galicia en los siglos XVI y XVII", TeatrEsco. Revista del Antiguo Teatro Escolar Hispánico, número 2, 2007, pp. 1-20.

15 COSTA RICO, Antón, Historia da Educación e da Cultura en Galicia (Séculos IV-XX), Vigo, Xerais, 2004; VIEITES, M. F., A configuración do sistema teatral galego, Compostela, Laiovento, 2003; VIEITES, M. F. (ed.), Cento vinte e cinco anos de teatro en lingua galega, Vigo, Galaxia, 2007.

16 VIEITES, M. F., "Os inicios da educación teatral en Galicia", Revista Galega de Teatro, número 33-34, 2002, pp. 36-40.

17 VIEITES, M. F. (ed.), Do novo teatro á nova dramaturxia (1965-1995), Vigo, Edicións Xerais, 1998.

18 VIEITES, M. F., Historia do teatro galego: unha lectura escénica, Santiago de Compostela, Dirección Xeral de Promoción Cultural, Xunta de Galicia, 2005.

19 Fronte aos autores que optan polo sintagma "Teoría da educación", apostamos polo termo Pedagoxía (teatral), seguindo, nesa dirección, ao profesor Alejandro SANVISENS MARFULL, no traballo titulado "Hacia una pedagogía de la comunicación”, en J. L. RODRÍGUEZ ILLERA (ed.), Educación y comunicación, Barcelona, Paidós, 1988, pp. 29-40.

20 VIEITES, M. F., "De la pedagogía teatral: disciplina académica, área de conocimiento y especialidad de estudios", en ADE/Teatro, número 136, 2011, pp. 144-159.

21 TEJERINA, Isabel, Dramatización y teatro infantil, Madrid, Siglo XXI, 1994. 
mesma. Nesa dirección, propoñemos neste traballo un modelo teórico que nos sirva para facer esa cartografía do campo, atendendo, como antes sinalamos, á súa complexidade e heteroxeneidade, ${ }^{22}$ pois, como haberemos de ver, prácticas educativas especificamente teatrais hai moitas e poden darse en tempos e espazos diversos, atendendo a usuarios variados e diferentes. Mais non deixa de ser menos certo que en moitos casos non quedou memoria escrita desas prácticas.

Sinalamos isto último porque non faremos un reconto exhaustivo e sistemático de todas e cada unha das experiencias das que temos constancia vivida, ou daquelas das que temos noticia a través de fontes diversas, ${ }^{23}$ nin tampouco faremos unha sistematización posterior de todas esas experiencias. Porén, pretendemos mostrar unha primeira panorámica do campo atendendo ás tipoloxías educativas que no mesmo podemos documentar, a partir, como dixemos, dunha visión que considera os que se veñen recoñecendo como escenarios e tempos da educación teatral. ${ }^{24}$

Queremos adoptar pois unha posición máis ben empírica e naturalista, é dicir, trataremos de partir da observación de prácticas propias da educación teatral, para despois agrupalas nun conxunto de ámbitos, unha proposta que poida ser obxecto de ulteriores estudos, comprobacións e refutacións. Facemos esta primeira exploración do campo para chegar, sequera como hipótese de traballo, a unha sorte de descrición xeral do mesmo, onde poidamos situar esas prácticas que documentamos ${ }^{25}$ ou as que, a falta de documentación dispoñible, nos limitamos a nomear, por termos memoria e conciencia de que existiron como tales.

Ten especial relevancia a cuestión metodolóxica, ${ }^{26}$ e non podemos ser alleos a moitos dos máis recentes desenvolvementos no ámbito da historiografía, que, en tantos casos, se alimentan das achegas que proveñen do campo das ciencias sociais para chegar á historiografía educativa. ${ }^{27} \mathrm{~A}$ documentación, e o proceso de recollida de datos, pode realizarse

22 Fóra do ámbito xeográfico peninsular existe un abano moi diversificado de prácticas educativas, que no eido da educación obrigatoria ten dado lugar a movementos de ámbito nacional e internacional de especial relevancia. Nesa dirección cabe destacar a asociación IDEA que se ocupa da expresión dramática e teatral, e que conta cunha páxina web chea de documentación e recursos: http://www.idea-org.net/

23 Existe unha notable dispersión das experiencias realizadas, pois moitas veces non pasaron das paredes da aula ou do centro, e só en contadas ocasións foron obxecto de reflexión e posterior difusión. Revistas como As Roladas, Revista Galega de Educación, Revista Galega do Ensino, Cuadernos de Pedagogía, Revista Galega de Teatro, Cadernos da Escola Dramática Galega, e outras, dan conta dunha actividade certa e vizosa que queda aínda por analizar e sistematizar.

24 TRILLA, Jaume, "La educación do formal. Definición, conceptos básicos y ámbitos de aplicación", en Jaume SARRAMONA (ed.), La educación no formal, Barcelona, CEAC, 2002; TRILLA, J. Otras educaciones, Barcelona, Editorial Anthropos, 1996.

25 Por razóns de espazo limitámonos a sinalar ámbitos, sen citar de forma exhaustiva axentes, persoas, colectivos, experiencias... Ese traballo de documentación queda formulado para investigacións futuras.

26 BISQUERRA ALZINA, Rafael (coord.), Metodología de la investigación educativa, Madrid, La Muralla, 2004. 27 Pode ter especial relevancia a síntese que nos ofrece Julio ARÓSTEGUI, La investigación histórica: teoría y método, Barcelona, Crítica, 2005, ou a de Guy BOURDÉ e Hervé MARTIN, Las escuelas históricas, Madrid, Akal, 2004. Na historiografía educativa destacamos os traballos compilados en VIÑAO FRAGO, Antonio, e DE GABRIEL FERNÁNDEZ, Narciso (eds.), La investigación histórico-educativa: tendencias actuales, Barcelona, 
utilizando técnicas cuantitativas e cualitativas, ${ }^{28}$ e no noso caso ambas son necesarias para operar no territorio dos relatos obxectivos, ou que, cando menos, procuren a obxectividade. Por iso resulta tan importante a mirada sistémica, en tanto nos permite considerar elementos, estruturas e redes, así como as súas funcións, dende o que Edgar Morin definira como paradigma da complexidade. E a educación conforma, como a sanidade, un dos sistemas máis importantes e complexos.

A análise de contidos, ${ }^{29}$ a partir do necesario rastrexo de fontes documentais moi diversas debe ir acompañada de entrevistas a diferentes axentes e suxeitos, ${ }^{30}$ estudo de casos, ${ }^{31}$ estudos comparados con outras realidades educativas noutros países, ${ }^{32}$ historias de vida (de suxeitos, entidades, institucións), ${ }^{33}$ grupos de discusión..., ${ }^{34}$ para ir construíndo ese reconto, un "relato" obxectivo que nos permita describir, explicar, comprender e interpretar o que ten sido a historia da educación teatral en Galicia, e proxectar as conclusións no momento actual. En boa lóxica, cada época precisará de enfoques metodolóxicos específicos, xa que algúns dos sinalados no son posibles en momentos concretos.

Trátase dun campo interesante, en tanto se vincula con prácticas educativas reais que aconteceron e seguen acontecendo en tempos e espazos educativos moi diferentes, polo que se fai necesaria esa primeira cartografía que nos permita transitar con comodidade e seguridade da historia do teatro á historia da educación, e viceversa, tamén para mostrar a dimensión educativa evidente do teatro, ${ }^{35}$ e non só nunha perspectiva profesional, senón nunha perspectiva máis global e integral. Estamos pois ante liñas de traballo que, seguramente, con novas achegas por vir e con novas voces por xuntar, permitirán crear a medio

Editorial Ronsel, 1997, ou un traballo recente de Antón COSTA RICO, "Historia de la educación en España. Realidades, problemas y tendencias en el dominio de la investigación”, Cadernos de Historia da Educação, volume 10, número 2, 2011, pp. 11-44.

28 DÁVILA, Andrés, "Perspectivas metodológicas cualitativa y cuantitativa en las Ciencias Sociales", en DELGADO Juan Manuel e GUTIÉRREZ Juan (coords.), Métodos y técnicas cualitativas de investigación en las ciencias sociales, Barcelona, Técnos, 1999.

29 LÓPEZ-ARANGUREN, Eduardo, "El análisis de contenido", en VV. AA., El análisis de la realidad social. Métodos y técnicas de investigación, Madrid, Alianza Universidad, 1994.

30 ALONSO, Luis Enrique, "Sujeto y discurso: la entrevista abierta", en DELGADO, J. M. e GUTIÉRREZ, J. (coords.), op. cit.,; KVALE, Steinar, Las entrevistas en investigación cualitativa, Madrid, Morata, 2011.

31 SIMONS, Helen, El estudio de caso: Teoría y práctica, Madrid, Morata, 2011.

32 BELTRÁN, Miguel, "Cinco vías de acceso a la realidad social", en VV. AA., op. cit., supra 29. Recentemente publicamos a versión galega do libro de Gavin BOLTON, Drama as education. An argument for placing drama at the centre of the curriculum, sobre a consolidación da educación teatral na ensinanza primaria e secundaria en Inglaterra, e que sirve como contraste para analizar o acontecido en España. Vid., BOLTON, Gavin, A expresión dramática na educación, Vigo, Galaxia, 2009.

33 MARTÍNEZ, Miguel, Comportamiento humano. Nuevos métodos de investigación, México D.F., Trillas, 1989. 34 CANALES, Manuel e PEINADO, Anselmo, "Grupos de discusión", en DELGADO J. M. e GUTIÉRREZ, J. (coords.), op. cit..

35 Un dos primeiros traballos foi o que Peter SLADE publica en 1954 co título de Child Drama, e que a España chegou como Expresión dramática infantil, editado en Madrid, por Santillana en 1978. En datas máis recentes, 2003, os profesores Kathleen GALLAGHER e David BOOTH editaron o volume colectivo titulado How Theatre Educates. Convergences \& Counterpoints, publicado en Toronto pola University of Toronto Press. A bibliografía existente en inglés, francés, portugués ou alemán é tan numerosa como substantiva, tanto que se precisarían estudos específicos neste eido. 
prazo unha liña de investigación específica centrada no campo do teatro e da educación aquí en Galicia, pero que vai ter unha especial incidencia na renovación metodolóxica no eido dos estudos teatrais.

\section{Explorando o campo}

En sintonía coa visión impresionista da educación teatral antes sinalada, que precisa dunha aproximación teorética para definir a súa esencia e os seus trazos pertinentes, nunha primeira prospectiva diremos que o sintagma convídanos a considerar prácticas educativas en función das finalidades que seguen:

(a) Educación para o teatro, na que o teatro, como arte e como práctica escénica, constitúe a finalidade última dos procesos de ensinanza e aprendizaxe, e de toda actividade formativa. Aquí podemos encaixar desde un curso de formación en comedia da arte para actores, ata un curso sobre teatro xaponés nun club de espectadores; pero tamén todos aqueles ámbitos de formación que se ocupan da xestión ou da tecnoloxía teatral, que con frecuencia se esquecen, como se o teatro fose patrimonio exclusivo dos artistas que se sitúan enriba dun escenario. Cando falamos dese "educar para o teatro", consideramos a educación de todas as persoas que traballan no campo, a través de procesos propios da expresión e da comunicación teatral, desde un actor a un técnico de escena. Falamos, en consecuencia, dunha formación profesional e utilizamos o termo "profesional" en tanto esa formación ten unha dimensión aplicada, vinculada cunha praxe, razón pola que durante moitos años as escolas consideradas técnicas levaban o nome de escolas profesionais. Aínda hoxe a Yale University conserva a denominación "professional school" para determinados centros, entre os que está a súa "School of Drama".

(b) Educación polo teatro, que fai referencia ao feito de que a través do teatro, é dicir, por medio de actividades de moi diversa factura, se desenvolven accións de formación vinculadas a contidos doutras áreas como historia, xeografía, xeometría, coñecemento do medio natural... ${ }^{36}$ Aquí, o teatro pasa a ter unha dimensión instrumental, grazas a todo un conxunto de procedementos (dramatización, xogo dramático, xogo de roles, creación colectiva, lecturas dramatizadas...), que se poñen ao servizo duns procesos de ensinanza e aprendizaxe, e de actividades formativas con finalidades propias. ${ }^{37}$ Podemos considerar, de igual modo, actividades que non se desenvolven na aula ou no centro educativo, pois en diversos campos da intervención socioeducativa ${ }^{38}$ se fai uso, por veces extensivo e intensivo, de técnicas dramáticas. ${ }^{39}$ Un caso interesante

36 No volume coordinado por José DANTAS, M. F. VIEITES e Marcelino de SOUSA, Teatro e intervenção social, editado en Chaves, Portugal, por Intervenção, Associação para a Promoção e Divulgação Cultural, en 2012, recóllense algunhas experiencias realizadas en Galicia nese campo.

37 RODRÍGUEZ LÓPEZ-VÁZQUEZ, Alfredo (ed.), Simposio "O teatro e o seu ensino", A Coruña, Servizo de Publicacións da Universidade de A Coruña, 1993.

38 CARIDE, José A. e VIEITES, M. F. (eds.), De la Educación Social a la Animación teatral, Gijón, TREA, 2006. 39 CRUZ, Melania P., "AXÚDA-ME, um projecto de implicação social. A sociedade como meio necesario para a inclussão", en J. DANTAS, M. F.VIEITES e M. de SOUSA (eds.), Teatro e intervenção social, Chaves, Intervenção, 
é o da Pedagoxía terapéutica, con prácticas que se sitúan a medio camiño entre as ciencias da saúde, as ciencias da conduta e as ciencias da educación, pero tamén dos usos e utilidades que os procedementos propios da expresión dramática e teatral poden ter no campo de determinadas terapias. ${ }^{40}$

(c) Educación no teatro, en tanto o teatro implique procesos de expresión, creación, comunicación e recepción que permiten crear un marco, unha escena, ${ }^{41}$ no que poñer en marcha un conxunto de actividades cunha dimensión a un tempo integral e transversal, e que nin se vinculan co teatro como manifestación artística nin con outros contidos culturais propios doutras disciplinas do currículo ou con outros saberes, senón co que se consideran competencias básicas para o desenvolvemento da persoa: sociabilidade, comunicación, creatividade, resolución de problemas, cooperación, espontaneidade, xogo de roles, comprensión da alteridade, e tantas máis, que se poden desenvolver plenamente a través das actividades propias da expresión dramática, fundamentalmente, e da expresión teatral ${ }^{42}$, e que tanto teñen que ver coa condición da persoa como actor social. ${ }^{43}$ Por razóns semellantes ás sinaladas no apartado anterior, esta educación no teatro pode darse en espazos non necesariamente escolares, pois con frecuencia os procesos propios da expresión dramática se utilizan nos máis diversos programas que pretenden lograr obxectivos idénticos aos que se programan nun centro educativo, pois en tanto permiten crear un marco ficticio de exploración de mundos e de roles, eses procesos contribúen a que os suxeitos recuperen a voz, a palabra, e a acción, para expresar o seu mundo e reconstruír a súa experiencia, camiño da recuperación crítica do seu lugar no corpo social e da emancipación, como quería Paulo Freire.

Nos casos (a) e (c) estariamos a falar, en sentido estrito, de educación teatral, pois desenvolver as competencias propias da expresión teatral ou da expresión dramática é a finalidade do proceso educativo, en tanto que en (b) a finalidade é outra, xa que ambas formas de expresión a través do rol, a través da conduta, supoñen un medio, unha fe-

2012, pp. 249-26.

40 Unha aproximación ao campo, desde a nosa perspectiva, pode atoparse na colectánea Animaçâo, artes e terapias, que recolle as actas do I Congresso Internacional de Animação Artes e Terapias, coordinado por J. DANTAS, M. F. VIEITES e M. de SOUSA, e editado en 2007 por Intervenção.

41 WINNICOTT, D. W., Realidad y Juego, Barcelona, Gedisa, 1979. Resulta moi interesante a proposta en torno ao que se define como "obxecto transicional", que nos permite falar dun "espazo transicional", ese espazo que permite transicións entre realidade e ficción e entre roles, tan propias do teatro.

42 VIEITES, M. F., "Teatro, Expresión Dramática e Educación en Galicia”, Revista Galega de Teatro, nำ 9, 1993, pp. 7-23; "A Expresión dramática no ensino primario", Revista Galega de Educación, nำ16, 1993, pp. 34-39; "0 ensino teatral en Galicia", Revista Galega de Educación, ํㅜ28, 1997, pp. 6-14.

43 Lembramos aquí os traballos realizados por sociólogos coma Kenneth Burke ou Erving Goffman, en torno ao que se podería denominar conduta dramática da persoa, asentada no xogo de roles. Vid., COMBS, James E., e MISCHE, Michael (eds.), Drama in Life; The Uses of Communication in Society, New York, Hastings House, 1976; GOFFMAN, Erving, La presentación de la persona en la vida cotidiana, Buenos Aires, Amorrortu, 2006 (1 $1^{\text {a }}$ edición de 1959). 
rramenta, procedementos. ${ }^{44}$ Nunha primeira proposta de diferenciación, poderamos falar dunha Educación Teatral (ET) orientada a unha formación académica e profesional especificamente teatral, e dunha ET orientada á formación integral a partir de disciplinas como a expresión dramática ou a expresión teatral. Habería que considerar aquela Educación polo Teatro que se vincula con outros saberes e ámbitos do ser e do facer. Teríamos entón unha ET xeral, unha ET especializada e unha ET instrumental. Trátase dunha proposta tentativa nun campo aínda por explorar e por delimitar, por iso utilizamos o condicional, pois é probable que nalgún momento se propoñan denominacións máis precisas e que susciten maior consenso. En todo caso, as tres modalidades propostas de educación teatral deben ser obxecto do estudo, tanto por parte desa disciplina que queremos conformar baixo a denominación de Historia da educación teatral, como desoutra disciplina que denominamos Pedagoxía teatral.

Nunha visión complementaria, e seguindo as pautas da Pedagoxía xeral, cabería considerar os tempos e os espazos da educación, é dicir, os que se veñen denominando como escenarios da educación. ${ }^{45}$ Para iso podemos seguir a coñecida tripartición do sistema educativo que propoñían Phillip H. Coombs e Manzoor Ahmed, ao distinguir tres modos de educación: informal, formal e non formal, ${ }^{46}$ sendo a primeira aquela que 0 individuo realiza ao longo da súa vida mediante experiencias diarias de relación co medio, a segunda a que ten lugar no marco do sistema educativo, e a terceira aquela que estando organizada e sistematizada se realiza fóra do sistema educativo e non conduce a unha titulación oficial. Esta tripartición ten provocado debates diversos, referidos sobre todo ao feito de que se poida falar ou non de educación informal naqueles casos en que non exista unha intencionalidade educativa por parte do emisor e/ou do receptor, ou non se dea unha comunicación bidireccional.

Non hai dúbida de que da lectura dun programa de man da Mostra Internacional de Teatro de Ribadavia, se pode derivar un aumento do caudal de coñecementos do lector, ou de que o feito de mirar un espectáculo na dita Mostra pode ser fonte de coñecemento para o espectador, pero resulta difícil conxugar unha vontade educativa por parte dun emisor, que necesariamente condicionaría a dimensión formal e os contidos da mensaxe, cunha vontade idéntica por parte dun receptor, o que modificaría a súa recepción. A que se denomina informal non é, propiamente, educación, en tanto definamos esta como un proceso de comunicación entre dúas persoas nas que unha delas asume o rol discente e a outra o rol docente. Nós partimos, en efecto, de considerar a educación como un proceso de comunicación, intencional e voluntario, e para os obxectivos deste traballo propoñemos

44 Unha aproximación ao concepto de "conduta dramática" aparece formulada no traballo "De la teatrología: ¿Disciplina o marco disciplinar?", incluído no volume Teatrología. Nuevas perspectivas, editado por Carlos RODRÍGUEZ e M. F. VIEITES, Ciudad Real, Ñaque Editora, 2010, pp. 13-35.

45 A consideración da aula como escena é unha proposta ben interesante, á que Seymour B. SARASON dedicou o libro La enseñanza como arte de representación, Buenos Aires, Amorrortu, 2002. Un enfoque sumamente suxestivo que propón liñas de traballo que permiten entender a educación ao abeiro das teorías da comunicación e do xogo de roles.

46 COOMBS, P. H., e AHMED, M., La lucha contra la pobreza rural, El aporte de la educación no formal, Madrid, Tecnos, 1975, p. 27. 
diferenciar entre educación regulada, non regulada, e aberta, se ben non deixemos de recoñecer que existen prácticas escénicas que posúen unha clara vontade de intervención social, como ese conxunto de manifestacións singulares que foron os teatros de axitación e propaganda en toda Europa e América durante todo o século XX. ${ }^{47}$

En efecto, considerando as moi diversas experiencias de educación teatral que se veñen desenvolvendo en Galicia, e tendo en conta a maneira en que se concibe, organiza e implementa a acción educativa podemos establecer unha serie de parámetros diferenciais, como a existencia ou non dun currículo oficial, que conduce ou non a unha titulación oficial, a necesidade de contar con profesorado habilitado e de centros con requisitos mínimos, a selección do alumnado e os requisitos previos, os criterios para a promoción de curso..., o que nos levaría á formación regulada e oficial, presente en escolas, institutos e centros de formación.

Na educación non regulada, que se pode dar en moitas academias, aulas de teatro, e outros centros ou espazos de acción cultural e/ou socioeducativa, desde unha asociación a unha fundación, existen procesos sistemáticos, organizados, e que en ocasións conducen á obtención de diplomas e outros recoñecementos, pero que carecen de validez oficial, ben que atopemos unha excepción nos denominados cursos de formación ocupacional, ${ }^{48}$ que esixen centros homologados e profesorado igualmente habilitado polas administracións públicas, o que os sitúa no campo da educación formal.

Como sinalamos nun traballo anterior, ${ }^{49}$ e considerando as propostas de diversos autores que utilizan parámetros varios para diferenciar o formal, o non formal e o informal, cómpren novas maneiras de denominar as "educacións", sobre todo a idea mesma da "educación informal". A finalidade da xa clásica "tripartición" era a de ser aplicada ao universo da educación para diferenciar tres tipos básicos de praxe educativa, e considerando o campo que nos ocupa nós propoñemos una nova terminoloxía para diferenciar entre (1) a formación regulada e oficial que se imparte en centros habilitados polas administracións educativas, (2) a formación formalizada, pero non regulada nin oficial, que se imparte en centros moi diversos, e (3) a formación aberta que se pode dar en calquera lugar, e que carece do carácter formalizado e sistemático das dúas anteriores, pero que cumpre finalidades educativas e formativas como as dúas anteriores..$^{50}$

47 KUPPERS, Petra, Community Performance. An Introduction, Londres, Routledge, 2007.

48 Así, e a modo de exemplo, na Familia Profesional de Imaxe Persoal hai cursos de Maquillador/a (IMPP50), de Caracterizador/a (IMPP60), cunha duración media de 475 horas; na Familia Profesional de Imaxe e Son hai cursos coma o de lluminador/a (IMSG40), ou Rexedor/a de Escena (IMSA20), cunha duración media de 550 horas, e todos eles cun nivel 2 de cualificación. Recordemos que estes niveis se establecen no Marco Europeo das Cualificacións (European Qualifications Framework) para equiparar competencias no desempeño profesional. Nun principio se consideraron cinco niveis que agora pasaron a oito. http://traballo.xunta.es/listaxede-especialidades-formativas

49 VIEITES, M. F., "¿Informal, non formal e formal? Da educación e das súas tipoloxías. Unha proposta de análise", ADAXE, Revista de Estudos e Experiencias Educativas, número 17, 2002, pp. 7-24.

50 As casuísticas son diversas. Así, a formación aberta pode aparecer nun centro educativo de secundaria en que un profesor de matemáticas dirixe un grupo de teatro e, á súa maneira, ofrece formación básica a un alumnado que vai e vén, ou nun club de espectadores. Un sindicato pode ofrecer cursos de formación ocupacional nun dos 
Así pois, no universo educativo existirían tres ámbitos relacionados entre si, pero igualmente diferenciais, e tal vez exista unha maior necesidade de contraste entre a educación non regulada e a formación aberta, en tanto na primeira se dá un nivel maior de formalización e sistematización, ao punto de que en ocasións colle unha dimensión profesional, como pode ser o caso dunha escola de actores ou de técnicos de escena. ${ }^{51}$ Porén, se unha Escola Municipal de Teatro, unha Aula de Teatro ${ }^{52}$ ou unha Escola Superior de Arte Dramática poden ofrecer programas de formación no campo da educación non regulada e no da formación aberta, mais só a última os pode ofrecer no campo da regulada e oficial.

Finalmente cabería falar dunha sorte de "educación difusa", que ten carácter aleatorio, e que ten moito que ver cos procesos de aprendizaxe que o suxeito pode desenvolver por conta propia, o que nos leva ao campo da autoeducación. Ten carácter aleatorio pois depende da vontade, da atención e da disposición do suxeito, o que vai determinar que as aprendizaxes posibles se dean ou non. Un campo interesante é o dos espectáculos para a infancia e a mocidade, que en ocasións proclaman unha vontade educadora que, para concretarse, precisa da colaboración do espectador; é dicir, dunha comunicación bidireccional que implica ademais a descodificación dunhas mensaxes específicas, aquelas con dimensión educativa.

\section{Xogando coa lente}

No apartado anterior falabamos de liñas posibles para enfrontar a educación teatral na súa historia, atendendo a finalidades ou escenarios. Nunha mirada sistémica deberiamos considerar os elementos que configuran ese subcampo da educación (a teatral), que se organizaría en torno a ese feito esencial no que, por seguirmos a metáfora de Peter Brook, ${ }^{53}$ dúas persoas se encontran e no encontro unha asume 0 rol de docente e a outra 0 de discente. Nesa dirección, imos presentar agora os espazos e entidades que ofrecen educación teatral para dar conta da casuística, e farémolo desde unha perspectiva dobre, sincrónica e diacrónica, falando do que houbo, do que hai, e do que non hai. Son historias e relatos por construír.

centros creados con tal motivo, como a Fundación Forem de Comisións Obreiras, co que estariamos nun ámbito regulado e oficial, mentres que, noutra dirección, unha Escola Municipal de Teatro pode ofrecer cursos orientados á praxe profesional, pero desde un campo nin regulado nin oficial.

51 Así funciona por exemplo o Centro de Tecnoloxía do Espectáculo, escola de formación dependente do Ministerio de Educación, Cultura e Deporte. Noutra dirección, máis ambiciosa, está a Escola Superior de Técnicas das Artes do Espectáculo do Instituto do Teatro de Barcelona, que ofrece títulos propios en coordinación coa Universidade Politécnica de Cataluña.

52 As aulas de teatro universitarias por veces ofrecen cursos que se poden recoñecer como créditos de libre configuración.

53 Vid., El espacio vacío. Arte y técnica del teatro, Barcelona, Península, 1969, p. 9. 


\section{1.- Centros educativos de ensinanza obrigatoria..$^{54}$}

- Educación infantil e primaria. Non existen materias vinculadas coa educación teatral toda vez que a Expresión dramática, que contemplaba a LOXSE ${ }^{55}$ e que non foi impartida por falta de profesorado especializado ${ }^{56} \mathrm{e}$ de horas lectivas dispoñibles, desapareceu coa Lei Orgánica de Educación. Algúns centros sen embargo inclúen clases obrigatorias de Expresión dramática ou Dramatización no currículo de forma voluntaria; así acontece no Colexio Fingoy de Lugo (laico) ${ }^{57}$ ou no Colexio San Narciso de Marín (relixioso). A Lei de Educación de 1970 foi a que introduciu, a través dos programas renovados, a dramatización como área de expresión artística. ${ }^{58}$ Nestes centros, como tamén ocorre nos de educación secundaria, hai que considerar as prácticas e actividades propias dos obradoiros de teatro, que contan cunha longa tradición, teñen dado lugar a festivais e circuítos, e promovido experiencias ben interesantes.

- Educación secundaria obrigatoria. Non existen materias vinculadas coa educación teatral na actual ordenación educativa. Sen embargo, no marco das optativas, algúns centros conseguiron o recoñecemento de materias como "Expresión teatral" ou "Taller de Teatro" ${ }^{59}$ No pasado, en tempos do Bacharelato Unificado e Polivalente (ou BUP), nalgúns centros de Galicia impartiuse unha disciplina específica denominada "Creación e Escenificación Literarias", ${ }^{60}$ derivada da área de "Teatro y Expresión Corporal" que fixara con anterioridade o Ministerio de Educación. ${ }^{61}$ Como no caso anterior ten especial relevancia o teatro escolar.

- Centros de educación especial. Nalgúns destes centros, que presentan una tipoloxía moi variada, adóitanse utilizar recursos de carácter dramático ou teatral como dramatizacións, xogos e animacións, se ben as experiencias son pouco coñecidas. Situámonos nos territorios da pedagoxía terapéutica e das terapias da conduta. ${ }^{62}$ Tamén aquí, teñen relevancia os talleres de teatro como unha máis das actividades educativas do centro.

\footnotetext{
54 VIEITES, M. F., "Sobre promesas y programas. Reflexiones en torno a la enseñanza teatral y su necesaria normalización", ADE/Teatro, número 52-53, 1996, pp. 98-106.

55 Lei Orgánica 1/1990, publicada no Boletín Oficial do Estado do 4 de outubro de 1990.

56 VIEITES, M. F., "Expresión dramática y formación docente", Comunidad Escolar, 21 de abril, 1993, p. 3.

57 HERRERO FIGUEROA, Araceli, "O teatro en Fingoi", Cadernos da Escola Dramática Galega, número 8, 1990. 58 CARPENTE, Bernardo, "Juego dramático en el Ciclo Medio", en Carlos HERÁNS (ed.), Teatro aula, aula teatro, Madrid, Acción Educativa, 1998; "O xogo dramático no ciclo medio", Revista Galega de Educación, número 8, 1989, pp. 39-42.

59 TEJERINA, l., op. cit.

60 Orde de 30 de Xuño de 1985, publicada do DOG do 20 de agosto de 1985.

61 Orde de 19 de Abril de 1985, publicada no BOE do 27 de abril de 1985.

62 MORALES RAMÓN, Ermel, "Trastornos do espectro do autismo: terapia grupal e teatro de texto", Maremagnum, número 14, 2010, pp. 51-58.
} 


\section{2.- Centros educativos de ensinanza posobrigatoria.}

- Centros de secundaria con bacharelato, nos que a ensinanza teatral non existe, a excepción do denominado Bacharelato de Artes na opción de Artes Escénicas, Música e Danza, que contempla unha única materia denominada "Artes escénicas", con catro horas semanais e que se pode impartir en primeiro ou segundo curso..$^{63}$ Como no caso anterior, colle especial relevancia o teatro escolar, que, no seu conxunto, podería conformar un interesante obxecto de investigación, en diferentes direccións, desde as escollas textuais até as estéticas, sen esquecer os contidos educativos implícitos ou explícitos, ou os procesos de recepción.

- Centros de formación profesional regrada. No existen, a diferenza doutros países, ciclos formativos específicos. Nun tempo, o Ciclo Superior de Animación Sociocultural incorporaba un módulo de formación en expresión teatral que desapareceu coa regulación definitiva dos Ciclos en Grao Medio e Grao Superior. Desde o Instituto do Teatro de Barcelona vénse insistindo na necesidade de crear unha familia profesional para a formación de técnicos vinculados coas artes do espectáculo sen éxito algún. ${ }^{64}$

- Centros de formación ocupacional. Non destacan precisamente por realizar cursos propios das actividades escénicas ben que estean regulados cursos vinculados con áreas como caracterización ou técnicas do espectáculo.

\section{3.- Centros de educación superior.}

- Materias de carácter teatral. Nalgunhas Escolas Universitarias de Formación do Profesorado (hoxe Facultades de Educación con Graos en Educación Infantil e Educación Primaria, entre outros) existiron no seu día materias optativas vinculadas coa Expresión dramática, ao ser esta una materia específica integrada coa LOXSE no currículo da Educación Infantil e da Educación Primaria, e que se impartían desde a área de Didáctica da Literatura. Esas materias desapareceron nos novos graos. Por outra banda, en titulacións como Filoloxía, Ciencias da Información ou Historia, aparecen e desaparecen materias cunha orientación e uns contidos netamente teatrais que serven como complementos de formación en especialidades de estudo relacionadas coa arte teatral.

- Titulacións propias. Na Universidade da Coruña púxose en marcha anos atrás un título propio en Pedagoxía teatral, equivalente a unha diplomatura. ${ }^{65}$

- Titulacións oficiais. En 2005 ponse en marcha a Escola Superior de Arte Dramática que a día de hoxe ofrece graos en Dirección escénica e dramaturxia, Escenografía

63 Decreto 126/2008, de 19 de xuño, publicado no DOG do 23 de xuño de 2008.

64 VIEITES, M. F., "Obras pendentes nun edificio en uso. Proposta para unha formación profesional específica nas artes do espectáculo", Revista Galega de Teatro, número 29, 2001, pp. 7-10.

65 RODRÍGUEZ LÓPEZ-VÁZQUEZ, A., "Unha proposta universitaria para o ensino do teatro, pedagoxía teatral", Revista Galega de Teatro, número 29, 2001, pp. 44-47. 
e Interpretación. ${ }^{66} \mathrm{~A}$ xénese e proceso de creación deste centro xa ten entidade suficiente para ser analizada cunha certa perspectiva. ${ }^{67}$

- Posgraos. Na Universidade de Santiago de Compostela impartiuse durante anos un Posgrao en Arte dramática con especialización en Interpretación e literatura contemporánea, coordinado polo profesor Anxo Abuín González. Esta iniciativa tería continuidade noutras propostas similares desenvolvidas desde a Universidade da Coruña polo profesor José María Paz Gago. Non existen programas de doutorado específicos en teatro, se ben se realizan e defenden teses de doutorado que teñen como obxecto os que se denominan estudos teatrais, pero que non conducen a un título de Doutor en Arte dramática, senón en Filoloxía, Historia ou Ciencias da Educación... Na actualidade a Universidade de Vigo ofrece un Máster en Artes Escénicas de carácter investigador con dous itinerarios, o de estudos literarios e escénicos, e 0 de pedagoxía teatral, ${ }^{68}$ e 0 correspondente programa de doutorado.

- Aulas de teatro universitarias. Quizais a primeira experiencia de formación neste eido sexa a que promove o profesor Armando Cotarelo Valledor a principios dos anos vinte do século $X X$, cando crea un grupo de teatro universitario, ${ }^{69}$ ao que seguirán outros nos anos cincuenta e sesenta, estes últimos nalgunha ocasión vinculados ou esgazados do SEU, sindicato de estudantes oficial no réxime do ditador Francisco Franco. ${ }^{70}$ Será en 1976 cando se cree a primeira "aula de teatro", na Universidade de Santiago, coordinada por Miguel Ángel Gómez Segade. Logo virán, a mediados dos oitenta, a Aula de Teatro da Universidade Nacional de Educación a Distancia de Pontevedra, coordinada por Miro Magariños, e a Aula de Teatro da Escola Universitaria de Formación do Profesorado de EXB de Pontevedra; coa creación das Universidades de Vigo e A Coruña, nacen as Aulas de Teatro das tres universidades con seccións nos diferentes campus: Santiago, ${ }^{71}$ Vigo, Orense, ${ }^{72}$ A Coruña, Pontevedra, ou Lugo. ${ }^{73}$ No ámbito da formación organízanse todo tipo

66 VIEITES, M. F., "A Escola Superior de Arte Dramática de Galicia: Unha realidade posible e necesaria", Revista Galega do Ensino, número 26, 2000, pp.163-182; RIOBOO, Pedro Pablo, "A Escola Superior de Arte Dramática de Galicia", Revista Galega de Teatro, número 44, 2005, pp. 7-10; SOLVEIRA, Ricardo, "La formación teatral: la ESAD de Galicia", ADE/Teatro, número 112, 2006, pp. 244-249.

67 Vid., Escaramuza, número 19, 2005.

68 Agroma aquí con forza outro tema interesante cal é o da investigación teatral, na súa historia e nas súas liñas fundamentais, que desde finais dos oitenta ten collido un pulo notable, tanto en teses de doutoramento presentadas como en materiais publicados de todo tipo.

69 RABUNHAL, Henrique, Textos e contextos do teatro galego. 1671-1936, Santiago de Compostela, Laiovento, 1994; TATO FONTAí̃NA, Laura, Historia do Teatro Galego. Das orixes a 1936, Vigo, A Nosa Terra, 1999.

70 SALGUEIRO, Roberto, "La Práctica escénica en la Universidad de Santiago de Compostela entre los años 1936 y 1975", en Luciano GARCÍA LORENZO (ed.), Aproximación al teatro español universitario (TEU), Madrid, Consejo Superior de Investigaciones Científicas, Instituto de la Lengua Española, 1999, pp. 173-221.

71 SALGUEIRO, R., "O ensino da Arte Dramática na Galicia", Información Teatral (Revista Galega de Teatro), número 9, 1993, pp. 45-49.

72 DACOSTA, Fernando, "Animación teatral na universidade", en M. F. VIEITES (coord.), Animación teatral, teorías, experiencias, materiais, Santiago de Compostela, Consello da Cultura Galega, 2000, pp. 425-453.

73 SALGUEIRO, R., "El Aula de Teatro de la Universidad de Santiago de Compostela y el teatro universitario gallego", ADE/Teatro, número 112, 2006, pp. 256-258. 
de cursos e en casos coma o de Ourense, ofrécese un programa con tres niveis, da iniciación ao perfeccionamento. ${ }^{74}$

\section{4.- Outros espazos de formación.}

- Escolas municipais de teatro. Trátase de entidades que ofrecen programas moi diversos orientados a colectivos variados, desde formación de actores e actrices até talleres de teatro para a infancia, a mocidade ou a terceira idade. Existe pois unha heteroxeneidade considerable, polo que encontramos propostas que queren desenvolver un programa de formación en interpretación (caso da EMT de Narón, ou da EMT de Vigo na súa primeira etapa) até as que se orientan a programas máis vinculados coa animación teatral de base (EMT de Villalba, Malpica, Cee...), ou as que ofrecen un programa de oferta múltiple (EMT de Porriño). Cómpre analizar con detemento aspectos básicos do funcionamento destas entidades considerando variables como oferta educativa, usuarios, profesorado, instalacións, recursos, programas, impacto e proxección comunitaria e sociocultural, e mesmo artística e profesional. ${ }^{75}$

- Escolas de teatro e centros privados de formación teatral. Os antecedentes deberiamos buscalos nalgunhas das experiencias pioneiras das que falaremos no epígrafe seguinte, pero aquí debemos destacar a Escola do Teatro Galego creada en torno a 1963 pola Asociación Cultural O Galo de Santiago de Compostela, e dirixida por Antonio Concheiro Caamaño, que poucos anos despois crearía en Betanzos un Aula Teatral no Liceo da localidade. Máis recentemente, aparecen espazos como Casahamlet, ${ }^{76}$ Teatro El Andamio, Espazo Aberto, Santart, ademais de salas de teatro que ofrecen programas de formación, como veremos. Nuns casos ofrecen programas de varios anos de formación e noutros cursos monográficos nas máis diversas disciplinas.

- Compañías de teatro. Con elas comeza, en realidade, a formación teatral en Galicia, no que podemos denominar modalidade de formación no posto de traballo (tamén para o campo non profesional, e diriamos formación no tempo do lecer). Así, no Liceo Brigantino, a compañía que pon en escena o que se considera como primeiro espectáculo do teatro galego contemporáneo, $A$ fonte do xuramento (1882), actuaba como director de escena Francisco Lumbreras, actor do que pouco sabemos pero que desenvolvera unha certa carreira profesional en Madrid e Asturias e que se retira na Coruña, continuando coa súa paixón teatral en liceos e

74 CUÑA BOVEDA, Anxos, "A formación permanente", en Manuel F. VIEITES (ed.), Teoría e técnica Teatral, Compostela, Laiovento, 1997, pp. 182-208; VV. AA., Vinte anos [da] Aula de Teatro Universitaria de Ourense, 1991-2010; Quince anos [da] MITEU, Mostra Internacional de Teatro Universitario, 1996-2010, Ourense, Difusora de Letras, Artes e Ideas, 2010.

75 VIEITES, M. F., "Unha escola municipal de teatro", Revista Galega de Teatro, número 53, 2007, pp. 18-24. 76 FERREIRA, Isaac, "Dez anos de Casahamlet: (1998-2008)", Casahamlet, numero 10, 2008. 
agrupacións recreativas e culturais. ${ }^{77}$ Despois virá a "Escuela Regional Gallega de Declamación"78 na que encontramos a Eduardo Sánchez Miño, discípulo de Emilio Mario, que pouco despois crea a primeira Escola Dramática Rexional, ou Escola Dramática Galega, en Ferrol, arredor de 1908 e coa que deseña un programa de residencia teatral no Teatro Romea da cidade. Seguirá o Conservatorio Nazonal do Arte Galego creado pola Irmandade da Fala da Coruña no que atopamos un cadro de declamación á fronte do que figura Fernando Osorio do Campo, formado no Conservatorio de Lisboa. ${ }^{79}$ Tras del virá o segundo proxecto de Escola Dramática Galega, á fronte da que temos a Leandro Carré Alvarellos, autor do primeiro "prontuario" de interpretación, ${ }^{80}$ conformado por un conxunto de notas que publica no semanario A Nosa Terra. As citadas escolas, polo que sabemos, intentaron establecer un programa de estudos básico, se ben non quedou constancia de cal puido ser, e ofrecían unha formación asentada nunha praxe da que tampouco temos documentación, agás os espectáculos realizados e as críticas recibidas.

Iniciada a ditadura, o teatro en Galicia tarda tempo en establecerse coma espazo de creación cultural. Pero as propostas retornarán con colectivos como a Asociación Cultural Iberoamericana da Coruña, da man de Antonio Naveira Goday, Cantigas e Agarimos de Santiago, con Rodolfo López-Veiga, ou Ditea, tamén en Santiago, con Agustín Magán. ${ }^{81}$ En todos estes colectivos se poñen en marcha procesos de formación de carácter gremial, nos que o mestre iniciaba aos novos integrantes do gremio teatral a través dun proceso propio dos aprendices, que en teatro se coñecían como "meritorios", e que van configurando un tímido tecido teatral que comeza a expandirse por toda Galicia nos anos sesenta coa irrupción do teatro independente en Ourense, Coruña, Vigo, Santiago e outros lugares, se ben moitas experiencias serán breves, puntuais. ${ }^{82}$

A finais dos anos sesenta e principios dos setenta comeza unha das xeiras máis importantes no teatro en Galicia, e no que fai á formación podemos dicir que é a época dos cursos, ${ }^{83}$ pois moitas compañías programan breves actividades de formación con xentes chegadas de fóra ou con persoas do país que trasladaban a outros colectivos a formación recibida dentro ou fóra do país. Entre eses colectivos

77 DÍAZ PARDEIRO, José Ricardo, La vida cultural en la Coruña. El teatro, 1882-1915, A Coruña, Galicia Editorial, 1992.

78 RABUNHAL CORGO, Henrique, "A Escola rexional de declamación: un fito na história teatral galega e coruñesa", Casahamlet, número 2, 2000, pp. 4-7.

79 DONEGA, Marino, "Un Home, unha aventura, un tempo: Fernando Osorio do Campo", Grial, número 33, 1971, pp. 333-338.

80 VIEITES, M. F., "Experiencias inaugurais de formación teatral en Galicia no tempo de Manuel Lugrís Freire", en Manuel Lugrís Freire: do texto ao escenario, Vigo, Galaxia, 2006, pp. 123-164.

81 RODRÍGUEZ VILLAR, Alejandra J., Cuando Compostela subió el telón, crónica sentimental de la década dorada del teatro santiagués: Ditea, 1960-1970, Compostela, Alvarellos, 2011.

82 RIOBÓ, P. P., O teatro contemporáneo galego, 1936-1996, A Coruña, Universidade de A Coruña, 1999.

83 Foi un proceso moi similar ao que ten lugar na renovación pedagóxica que se desenvolve en Escolas de Verán, nas que certamente tamén se programaron os primeiros cursos de introdución ao teatro escolar. 
cabe destacar Teatro Circo, máis tarde Escola Dramática Galega ${ }^{84}$, entidade esta última que crea un departamento de "didácticas" e que comezará a editar materiais educativos a través dos seus "Cuadernos". Na Sala Carral, creada en 1978, tamén se programan cursos, como xa se facía con ocasión das Jornadas de Teatro que se celebraban en Vigo a principios dos setenta. ${ }^{85} \mathrm{~A}$ tendencia a organizar cursos vai perdurar durante moito tempo e vai ser o marco de formación por excelencia, aínda que a veces se desenvolvan experiencias que intentan ir máis alá, como foi o caso do Obradoiro de Aprendizaxe Teatral de Antroido, creado en 1978 para a formación de persoas que puidesen traballar na compañía. Esa dinámica seguiu funcionando desde aquela, sexa a través de compañías, sexa nos locais dalgunhas desas compañías como a Sala Luís Seoane (A Coruña), Sala Galán (Santiago), Sala Nasa (Santiago), Ensalle (Vigo), El Andamio (A Coruña) ou Teatro Arte Livre (Vigo).

- Institucións, fundacións, asociacións e entidades diversas. Organizan cursos de formación inicial ou permanente, de actualización e de divulgación. Na listaxe podemos incluír desde o Centro Dramático Galego á Fundación Barrié, e desde a Asociación de Actores e Actrices de Galicia á Asociación de Titiriteiros. Incluso Festivais de Teatro como Xeración Nós de Ferrol Terra, Cangas ou Carballiño, entre outros, organizaron e organizan cursos de formación. Neste ámbito, temos que situar igualmente asociacións de moi diversa orientación, e colectivos do teatro non profesional, entre os que está tomando un pulo importante a Federación Galega do Teatro Amador (FEGATEA).

Até aquí unha breve panorámica de tempos e espazos para a educación teatral. Para completala, habería que considerar os axentes e os elementos que son propios do subsistema da educación teatral; por seguirmos coa tónica do traballo, sintetizamos a nosa presentación nunhas liñas xerais que orienten ulteriores indagacións:

- Profesorado, docentes, formadores. Cabería considerar a súa cualificación e a relación que mantén co colectivo de usuarios e co espazo onde ten lugar a formación, para analizar os tipos de proceso que se poñen en marcha: docente externo e interno, docente formador ou docente creador, mestres e mestras recoñecidos; ${ }^{86}$ en compañías, en salas ou en centros que xeran fluxos de alumnado. ${ }^{87}$ Cómpre considerar a traxectoria artística, docente ou investigadora

84 VISCAÍNHO FERNANDES, Carlos C., A Escola Dramática Galega na configuración do sistema teatral, Bertamiráns, Laiovento, 2007.

85 VIEITES, M. F., La nueva dramaturgia gallega. Estudio y antología, Publicaciones de la Asociación de Directores de Escena de España, Madrid, 1998.

86 VIEITES, M. F. "Docencia e investigación na traxectoria de Manuel Lourenzo. Un apuntamento", en Roberto PASCUAL (ed.), Palabra e acción. A obra de Manuel Lourenzo no sistema teatral galego, Lugo, TrisTram, 2006, pp. 131-149.

87 Resulta especialmente relevante considerar a traxectoria de salas de teatro como a Galán ou a Nasa en Santiago de Compostela en tanto se vinculan coa promoción de novas formas de entender a interpretación que se abeiran a iso que de denomina a "non-interpretación" na que o actor acaba sendo substituído por unha persoa 
de docentes e de compañías, ou da escola ou do movemento co que se vincula. Así, a modo de exemplo, hai preguntas especialmente pertinentes: que modelos de ensinanza e aprendizaxe se poñen en marcha?, que paradigmas se consideran no campo da interpretación, da expresión dramática, da formación oral...?, como se avalían eses procesos ou se contrastan os seus resultados?, existe algún tipo de confronto entre teorías e prácticas escénicas en función dos procesos de formación?

- Formación do profesorado e tipoloxías do mesmo. Habería que considerar a formación inicial e a permanente, os procedementos de habilitación e outras cuestións vinculadas co acceso ao exercicio profesional, así como os procesos de actualización. Cómpre analizar a formación dos profesores e profesoras que se ocupan das actividades teatrais en escolas e institutos ou que reciben cursos de formación teatral por razóns diversas. ${ }^{88}$ Igualmente, sería importante considerar as liñas de traballo desenvolvidas desde as instancias que na administración educativa se ocupan da formación permanente do profesorado, nestes momentos a través dos Centros de Formación e Recursos.

- Alumnado e tipoloxías, intereses e expectativas. Resulta moi interesante analizar as razóns polas que 0 alumando de secundaria ou bacharelato se achega ao mundo teatral, e saber o que espera encontrar nese mundo e nesas actividades. Tamén cabería considerar as necesidades de formación que poden demandar colectivos moi diversos pensando nos procesos de formación permanente, e analizar a proxección desa formación e a súa concreción en proxectos escénicos. Da mesma maneira é importante analizar outros aspectos como idade, sexo, estudos ou profesión na hora de considerar nunha perspectiva xeral os usuarios dos procesos de educación. Un campo aberto a moitas posibilidades, no que se debe considerar a percepción dos pais e nais, e da sociedade en xeral, en relación coas potencialidades ou logros da educación teatral.

- Os ámbitos de formación e as prácticas expresivas ou profesionais preferentes, no tempo e no espazo: expresión oral, expresión corporal, mimo, clown, interpretación, dirección escénica, escenografía, dramaturxia, animación teatral, pedagoxía teatral, teatro do oprimido, teatro social, teatro de obxectos... Tamén se poderían considerar as modalidades de curso e 0 seu formato e variantes, en canto a duración, programas, orientación básica, avaliación de resultados, transferencia de coñecementos a outras prácticas artísticas ou educativas...

escénica que acaba por ser una variante na conduta e presentación da persoa real que se sitúa no escenario. Vid., ZARRILLI, Phillip B., A interpretación (re)considerada, Vigo, Galaxia, 2010.

88 Os primeiros cursos teñen lugar en Escolas de Verán, en festivais de teatro ou en ciclos organizados por entidades diversas, o que permite que cheguen a Galicia persoas coma Carlos Fragateiro, Carlos Heráns, Alfredo Mantovani ou Franco Passatore, entre outros. 
- Correntes, escolas e metodoloxías de traballo dominantes en cada momento, ${ }^{89}$ desenvolvemento de liñas propias e apropiación de liñas procedentes do exterior, incidencia na praxe escénica e nos propios procesos de formación e creación. Aquí cabería considerar as boas prácticas, é dicir aqueles procesos de formación que gozan de aprobación e recoñecemento debido aos resultados acadados.

- Materiais elaborados en formatos diversos, desde revistas, ${ }^{90}$ ou libros, até produtos audiovisuais, e outros recursos, coma os cadernos dos espectáculos e as unidades didácticas, ou as revistas de información editadas polas compañías de teatro. ${ }^{91}$ Desde 1978 e ata os primeiros noventa, a Escola Dramática Galega, a través dos seus "cadernos"92 desenvolveu un traballo importante de divulgación de propostas de traballo, desde pequenos manuais con actividades ${ }^{93}$ a textos dramáticos para seren utilizados na escola, escritos por xentes coma Xoán Babarro, Ana María Fernández ou Xesús Pisón, e que van dar pulo a unha dramática infantil en lingua galega ${ }^{94}$ Posteriormente comezaron a aparecer volumes sobre praxe teatral ou coleccións de teatro en diferentes editoriais e revistas, destacando especialmente Vagalume, ASPG, Edicións Xerais, Edicións IrIndo, Ediciós do Castro, Sotelo Blanco, Bahía Edicións, Laiovento, Casahamlet, Universidade de A Coruña (a través do Arquivo Francisco Pillado), ou Galaxia. Colle pulo nestes últimos vinte anos a investigación teatral, e pouco a pouco vaise xerando unha bibliografía específica no eido da pedagoxía do teatro, dous eidos que xa precisan estudos específicos que analicen o traballo realizado.

Non hai dúbida de que esta breve relación de aspectos a considerar podería ser máis ampla, sobre todo para multiplicar o número de traballos de referencia nos ámbitos sinalados, e o número de notas a rodapé, pero debemos insistir en que se trata dunha

89 Como se dixo, estamos ante un dos campos máis interesantes, pois permite considerar as relación que Galicia mantén co exterior e as tendencias que se incorporan en moitos ámbitos da formación e da creación, $e$ as que non, e como esas apropiacións inflúen no desenvolvemento do sistema, da formación, da investigación ou da creación.

90 Por seren galegas e editarse en lingua galega, e prestar especial atención á nosa realidade, lembremos a Don Saturio, Ensaio, Bululú, Anuario Galego de Estudos Teatrais, xa desaparecidas, ou as actuais Revista Galega de Teatro (antes Información teatral), Escaramuza, Núa ou Fegatea; sen esquecer que outras revistas de ámbito estatal como Primer Acto, ADE/Teatro ou Artez tamén ofrecen información sobre aspectos concretos do acontecer teatral do país.

91 Lembramos, nesa dirección, as edicións da Compañía Luís Seoane, as do Centro Dramático Galego ou as de Teatro do Noroeste.

92 En 2010 David GARCÍA VIDAL presentaba na University of Birmingham unha tese de doutoramento baixo o título de "Teatro galego e construción nacional: os Cadernos da Escola Dramática Galega (1978-1994)", que ofrecía unha interesante aproximación aos materiais editados pola EDG desde unha perspectiva literaria, quedando sen analizar a perspectiva pedagóxica ou educativa. Pode consultarse en http://etheses.bham. ac.uk/972/

93 LAMAPEREIRA, Antón, Teatro na escola: materiais de traballo 1, Cadernos da Escola Dramática Galega, número 12, 1980.

94 VIEITES, M. F., "Literatura dramática e teatro para a infancia e a mocidade. Breve introducción para o seu estudio", en op. cit., supra 17, pp. 193-234. 
aproximación que non busca máis que definir algúns eidos de traballo para indagacións e investigacións por facer, e que precisan doutros espazos para a súa divulgación.

\section{Un proceso por comezar}

Ata aquí sinalamos as contornas dun campo que esixe algunhas indagacións exhaustivas que nos permitan reconstruír unha parte substantiva da nosa historia educativa e teatral. Malia que só en 2005 se crea en Galicia un centro superior oficial de formación en arte dramática, a ESAD de Galicia, a educación teatral non estivo ausente do noso país en ningún momento, e presenta, como puidemos ver, unha riqueza maior da que de primeiras cabería imaxinar. Por iso quizais a conclusión fundamental que poidamos sacar deste breve paseo polo campo sexa a necesidade de abordalo e de estudalo de forma integral, a través de varias incursións sistemáticas.

Temos diante nosa, en efecto, un campo que quizais en poucos anos nos permita consolidar unha liña de investigación arredor do que definimos como Historia da educación teatral e que, nunha perspectiva teórica e aplicada, conta cun abano moi amplo de posibilidades, se ben o alcance de todas elas vén determinado polo grao de desenvolvemento do sistema teatral propio, mais o desenvolvemento futuro dese sistema tamén vai depender dunha adecuada comprensión do pasado, a comprensión que nos ofrece a ciencia histórica, unha interpretación do pasado que poida iluminar o presente e alentar o futuro. Por iso cómpre impulsar a Historia da educación teatral. 